\title{
The effect of scapular strengthening exercise using elastic band on balance and quality of life in the old people
}

\author{
Sun-Young $\mathrm{Ha}^{1}$, Yun-Hee Sung ${ }^{1,2 * *}$ \\ 'Department of Physical Therapy, Graduate School, Kyungnam University, Changwon, Korea \\ ${ }^{2}$ Department of Physical Therapy, College of Health Sciences, Kyungnam University, Changwon, Korea
}

The old people are weakened and misaligned due to aging, and their balance and quality of life are reduced. We investigated that the effect of scapular strengthening exercise on balance and quality of life in the old people. A scapular strengthening exercise was applied to the experimental group, and the general conditioning exercise was applied to the control group for 40 min per session, 5 times a week, for a total of 4 weeks. As a result, the static balance and Y-balance test performance improved in the experimental group $(P<0.05)$. The physical function and mental health, and general health of 36 -item Short Form health survey improved in the experimental group $(P<0.05)$. Therefore, the scapular strengthening exercise could be suggested as an intervention method that could improve the balance and quality of life of the old people.

Keywords: Scapula, Elastic band, Balance, Quality of life

\section{INTRODUCTION}

Globally, the old people population continues to increase, and their health problems become a big issue as a result (Choi et al., 2011). The old people gradually weaken their muscle strength and muscle tone due to aging, and their muscle mass and basal metabolic rate decrease (Bechshøft et al., 2016; Brown et al., 2000). In addition, due to the decrease in the flexibility of the spine and the range of motion of the joint, the posture becomes bent, and a problem occurs in the posture alignment (Kado et al., 2004).

The scapula is an intermediate segment that connects the upper limb and the trunk, and the position and stability of the scapula influence the alignment of the spine (Magarey and Jones, 2003) and the antigravity activity of the trunk (Hazar Kanik et al., 2017). Weakness and dysfunction of the muscles around the scapula affect posture changes in the trunk, cervical and thoracic vertebrae (Moezy et al., 2014), reducing balance ability and affecting functional mobility (Granacher et al., 2013). A recent study reported that kypotic posture, a typical posture in the old people, increased the risk of falls (Choi et al., 2011; Kado et al., 2004). Therefore, posture change through scapular movement can have a positive effect on body function and balance (Shiravi et al., 2019).

Balance is the control and maintenance of posture against stimuli from the external environment (Cheng et al., 2001). For the old people, balance is the most basic and essential factor for leading independent daily life (Kaufman et al., 2001). As aging progresses, sensory functions (vision, vestibular organs, and proprioceptive sensations) decrease and balance ability is lost, increasing the risk of falls and consequently lowering the quality of life (Rogers et al., 2003). Therefore, balance ability is essential for improving the motor function of the old people (Prasertsakul et al., 2018).

The physical function (PH) of the old people is an important factor in determining the quality of life (Geirsdottir et al., 2012). Various interventions such as aerobic exercise, lower extremity resistance exercise, trunk strengthening exercise, and elastic band exercise have been applied to improve the $\mathrm{PH}$ of the old people (Granacher et al., 2013; Huang et al., 2017; Liao et al., 2018; Liberman et al., 2017). Among them, exercises using elastic band is more effective in increasing function of muscle strength and pre-
${ }^{*}$ Corresponding author: Yun-Hee Sung (D) https://orcid.org/0000-0002-4877-9784 Department of Physical Therapy, College of Health Sciences, Kyungnam University, 7 Kyungnamdaehak-ro, Masanhappo-gu, Changwon 51767, Korea Email: sungpt97@kyungnam.ac.kr

Received: March 7, 2021 / Accepted: April 10, 2021
This is an Open Access article distributed under the terms of the Creative Commons Attribution Non-Commercial License (https://creativecommons.org/licenses/by-nc/4.0/) which permits unrestricted non-commercial use, distribution, and reproduction in any medium, provided the original work is properly cited. 
venting damage than bare body resistance exercises, and can provide more advantages in improving muscle strength, endurance, flexibility, and balance (Huang et al., 2017; Liao et al., 2018). In addition, it is an effective intervention method for the old people because it is easy to control the strength of resistance and helps strengthen muscles (Liao et al., 2018).

Interventions for improving motor function in the old people have been reported, but the effect of scapular strengthening exercise using an elastic band on motor function in the old people is rare. Therefore, we determined the effect of scapular strengthening exercise using elastic band on the balance and quality of life in the old people.

\section{MATERIALS AND METHODS}

\section{Participants}

This study was conducted on the old people using the Senior Welfare Center located in Changwon. Inclusion criteria are: (a) those who have not had difficulty walking or fall within the last 3 months, (b) those who have no serious pain, musculoskeletal damage, or neurological damage, (c) those who have spinal disorders and related diseases, (d) those who understand the instructions of the examiner and can perform them. Exclusion criteria are (a) a person with acute inflammation, (b) a person with visual and hearing problems. All participants understood the content of the study and participated voluntarily. This study was organized after the approval of the Research Ethics Committee of Kyungnam University (104060-A-2020-021). The selected participants were randomly divided into two groups. Romberg's test, Y-balance test, and quality of life (36-item Short Form health survey, SF-36) were applied in both groups before and after intervention, respectively.

\section{Intervention}

The control group applied general conditioning exercise and the experimental group applied scapular strengthening exercise using elastic band (Spiralista, Brno, Czech Republic) exercise. All groups exercised for $40 \mathrm{~min}$ per session, 5 times a week, for a total 4 weeks. The exercise was conducted as a group exercise. Exercise programs for experimental group are shown in Table 1.

\section{Static balance}

Romberg test was to measure the static balance ability, and the Balancia software program (Balancia software ver. 2.0, Mintosys, Seoul, Korea) was used for data collection. Participants looked straight ahead on the Wii balance board and stood with both feet together. Participants opened their eyes, closed their eyes, and held each for $1 \mathrm{~min}$.

\section{Y-balance}

To measure the flexibility and balance of the lower limbs, a professional Y-balance test kit (Functional Movement System, Lynchburg, VA, USA) was used. The participants stood in the center of the Y-balance board and maintained the balance by extending one leg as far as possible in each direction of the anterior (ANT), posterior-medial (PM), and posterior-lateral (PL). It was measured based on the dominant foot, and the average value was used by measuring twice, and the unit is $\mathrm{cm}$. For Y-balance, the interrater reliability is intraclass correlation (ICC) $=0.85-0.91$, and the intrarater reliability is ICC $=0.99-1.00$ (Plisky et al., 2009).

\section{Quality of life}

A Korean SF-36 is a questionnaire form that the subject fills out to evaluate the quality of life related to health, with a total of 36 questions, $\mathrm{PH}$, vitality, body pain, general health $(\mathrm{GH})$ perception, physical role function, social function, emotional role function, and mental health (MH) (Han et al., 2004). Each item was calculated according to the Likert scale, and was calculated by applying a weight based on the score from 1 to 6 according to the question. Each scored item was summed for each item, and the

Table 1. Elastic band exercise program

\begin{tabular}{|c|c|c|c|}
\hline Content & Exercise & Time & Repetition $\times$ set \\
\hline Warm-up & Stretching the muscles around the shoulder and trunk & $5 \min$ & 10 times $(40 \mathrm{sec}) \times 5$ set \\
\hline \multirow[t]{5}{*}{ Main exercise } & 1. In sitting position, put an elastic band in one hand and exercise scapular adduction & \multirow{5}{*}{$\begin{array}{l}30 \text { min ( } 5 \text { min per } \\
\text { exercise) }\end{array}$} & 20 sec rest per set \\
\hline & 2. In standing position, put an elastic band in one hand and exercise scapular adduction & & \\
\hline & 3. In standing position, put an elastic band on both hands and exercise scapular adduction & & \\
\hline & 4. In standing position, put an elastic band on both hands, scapular adduction + shoulder external rotation & & \\
\hline & 5. Holding sticks in both hands, put an elastic band on both feet, and alternate movement of limbs & & \\
\hline Cool-down & Stretching the muscles around the shoulder and trunk & $5 \min$ & \\
\hline
\end{tabular}


total score was converted into a 100-point perfect score.

Converted score $=($ original score of category-minimum raw score $) \times 100$ /origin score range

\section{Statistical analysis}

IBM SPSS ver. 18.0 (IBM Co., Armonk, NY, USA) for window was used for statistical analysis. Shapiro-Wilks test was performed to test the normality of variables. The independent $t$-test was used for the difference between groups, and the paired $t$-test was used for the differences within the group. All statistical significance levels $(\alpha)$ were set to 0.05 .

Table 2. General characteristics of the participants ( $N=24)$

\begin{tabular}{lccc}
\hline Variable & Experimental $(\mathrm{n}=12)$ & Control $(\mathrm{n}=12)$ & $P$-value \\
\hline Gender, male:female & $1: 11$ & $3: 9$ & \\
Age $(\mathrm{yr})$ & $74.17 \pm 5.67$ & $73.75 \pm 5.84$ & 0.86 \\
Height $(\mathrm{cm})$ & $158.00 \pm 7.27$ & $156.50 \pm 10.40$ & 0.33 \\
Weight $(\mathrm{kg})$ & $62.08 \pm 8.25$ & $58.75 \pm 8.46$ & 0.67 \\
\hline
\end{tabular}

Values are presented as number or mean \pm standard deviation.

\section{RESULTS}

\section{General characteristics of the participants}

Table 2 shows the general characteristics of the participants.

\section{Static balance}

With the eyes open, there were significant differences within the experimental group in the path velocity, path length, and path area $(P<0.05)$. There were significant differences between groups in the change (post-pre) in path velocity, path length, and path area $(P<0.05)$. With the eyes closed, there were significant differences within the experimental group in the path velocity, path length, and path area $(P<0.05)$. There were significant differences between groups in path area before, after intervention and change (post-pre) $(P<0.05)$ (Table 3).

\section{Dynamic balance}

In the ANT and PM, it was significantly increased within the experimental group $(P<0.05)$. There were significant differences between groups in ANT in change (post-pre) $(P<0.05)$ (Table 4).

Table 3. Changes of Romberg test with eyes open and closed ( $N=24)$

\begin{tabular}{|c|c|c|c|c|c|c|}
\hline \multirow{2}{*}{ Variable } & \multicolumn{3}{|c|}{ Experimental } & \multicolumn{3}{|c|}{ Control } \\
\hline & Pre & Post & Post-Pre & Pre & Post & Post-Pre \\
\hline \multicolumn{7}{|l|}{ EO } \\
\hline Path velocity $(\mathrm{cm} / \mathrm{sec})$ & $3.10 \pm 0.53$ & $2.53 \pm 0.28^{*}$ & $-0.53 \pm 0.30^{\dagger}$ & $3.02 \pm 0.44$ & $2.90 \pm 0.38$ & $-0.12 \pm 0.43$ \\
\hline Path length (cm) & $97.15 \pm 17.16$ & $79.68 \pm 8.09^{*}$ & $-15.99 \pm 9.01^{\dagger}$ & $90.65 \pm 13.54$ & $85.40 \pm 15.62$ & $-5.24 \pm 16.48$ \\
\hline Path area $\left(\mathrm{mm}^{2}\right)$ & $3.23 \pm 0.57$ & $2.65 \pm 0.27^{*}$ & $-0.58 \pm 0.48^{\dagger}$ & $2.82 \pm 0.73$ & $2.84 \pm 0.44$ & $0.01 \pm 0.54$ \\
\hline \multicolumn{7}{|l|}{$\mathrm{EC}$} \\
\hline Path velocity (cm/sec) & $3.96 \pm 1.23$ & $2.82 \pm 0.54^{*}$ & $-1.13 \pm 0.91$ & $3.32 \pm 1.06$ & $2.83 \pm 0.41$ & $-0.48 \pm 1.06$ \\
\hline Path length (cm) & $111.34 \pm 36.73$ & $84.79 \pm 16.31^{*}$ & $-33.55 \pm 27.48$ & $99.35 \pm 32.15$ & $82.41 \pm 17.42$ & $-16.94 \pm 33.42$ \\
\hline Path area $\left(\mathrm{mm}^{2}\right)$ & $7.77 \pm 2.39^{\dagger}$ & $2.30 \pm 0.91^{*,+}$ & $-6.83 \pm 5.31^{\dagger}$ & $2.13 \pm 1.24$ & $2.65 \pm 5.31^{*}$ & $2.65 \pm 2.28$ \\
\hline
\end{tabular}

Values are presented as mean \pm standard deviation.

EO, eye open; EC, eye closed.

${ }^{*}$ Significantly different from pre $(P<0.05) .{ }^{\dagger}$ Significantly different from control $(P<0.05)$.

Table 4. Changes of Y-balance test ( $\mathrm{N}=24)$

\begin{tabular}{|c|c|c|c|c|c|c|}
\hline \multirow{2}{*}{ Variable } & \multicolumn{3}{|c|}{ Experimental } & \multicolumn{3}{|c|}{ Control } \\
\hline & Pre & Post & Post-Pre & Pre & Post & Post-Pre \\
\hline ANT (cm) & $63.50 \pm 10.05$ & $78.29 \pm 9.22^{*}$ & $14.79 \pm 10.01^{\dagger}$ & $71.10 \pm 16.07$ & $76.69 \pm 14.52^{*}$ & $5.58 \pm 5.88$ \\
\hline PM (cm) & $60.91 \pm 12.68$ & $71.00 \pm 6.90^{*}$ & $10.08 \pm 12.89$ & $61.46 \pm 17.26$ & $66.99 \pm 16.32^{*}$ & $5.53 \pm 7.79$ \\
\hline $\mathrm{PL}(\mathrm{cm})$ & $67.90 \pm 14.88$ & $72.63 \pm 7.36$ & $4.72 \pm 16.87$ & $62.99 \pm 18.98$ & $70.21 \pm 17.34^{*}$ & $7.22 \pm 7.75$ \\
\hline
\end{tabular}

Values are presented as mean \pm standard deviation.

${ }^{*}$ Significantly different from pre $(P<0.05)$. 'Significantly different from control $(P<0.05)$.

ANT, anterior; PM, posterior-medial; PL, posterior-lateral. 
Table 5. Changes of quality of life $(\mathrm{N}=24)$

\begin{tabular}{|c|c|c|c|c|c|c|}
\hline \multirow{2}{*}{ Variable } & \multicolumn{3}{|c|}{ Experimental } & \multicolumn{3}{|c|}{ Control } \\
\hline & Pre & Post & Post-Pre & Pre & Post & Post-Pre \\
\hline PF & $75.41 \pm 16.57$ & $81.25 \pm 13.83^{*}$ & $5.83 \pm 8.21$ & $72.50 \pm 20.61$ & $74.58 \pm 13.56$ & $2.08 \pm 14.37$ \\
\hline $\mathrm{RP}$ & $68.75 \pm 46.61$ & $70.83 \pm 38.18$ & $2.08 \pm 22.50$ & $47.91 \pm 37.62$ & $45.83 \pm 38.18$ & $-2.08 \pm 39.10$ \\
\hline RE & $76.03 \pm 32.00$ & $92.56 \pm 12.93$ & $16.51 \pm 35.53$ & $80.70 \pm 24.04$ & $82.31 \pm 18.91$ & $1.61 \pm 16.34$ \\
\hline VT & $59.17 \pm 18.80$ & $61.66 \pm 18.38$ & $2.50 \pm 9.65$ & $57.92 \pm 26.58$ & $55.00 \pm 17.83$ & $-2.91 \pm 16.30$ \\
\hline $\mathrm{MH}$ & $78.33 \pm 18.71$ & $82.18 \pm 11.36^{\dagger}$ & $3.84 \pm 15.30$ & $65.33 \pm 20.34$ & $62.00 \pm 18.25$ & $-3.33 \pm 19.65$ \\
\hline SF & $73.95 \pm 13.54$ & $80.20 \pm 12.45$ & $6.25 \pm 14.59$ & $67.04 \pm 21.50$ & $76.13 \pm 18.03$ & $9.09 \pm 27.22$ \\
\hline $\mathrm{BP}$ & $71.59 \pm 18.65$ & $72.91 \pm 23.22$ & $1.32 \pm 18.89$ & $62.25 \pm 24.20$ & $64.25 \pm 27.22$ & $2.00 \pm 24.44$ \\
\hline $\mathrm{GH}$ & $63.18 \pm 22.18$ & $64.09 \pm 17.42^{\dagger}$ & $0.90 \pm 11.64$ & $55.55 \pm 13.55$ & $50.55 \pm 10.75$ & $-5.00 \pm 9.29$ \\
\hline
\end{tabular}

Values are presented as mean \pm standard deviation (score).

PF, physical function; RP, role limitation due to physical health problems; RE, role limitation due to physical emotional problems; VT, vitality; MH, mental health; SF, social function; $\mathrm{BP}$, bodily pain; $\mathrm{GH}$, general health.

${ }^{*}$ Significantly different from pre $(P<0.05)$. ${ }^{~}$ Significantly different from control $(P<0.05)$.

\section{Quality of life}

There was a significant difference in $\mathrm{PH}$ within the experimental group $(P<0.05)$. There were significant differences between the groups in $\mathrm{MH}$ and $\mathrm{GH}(P<0.05)$ (Table 5 ).

\section{DISCUSSION}

Decreased PH in the old people causes secondary problems such as daily life restrictions, reduced range of activities, and falls, thereby lowering the quality of life and acting as a factor that hinders independent living (Hyndman et al., 2006; Regterschot et al., 2014). Therefore, the purpose of this study was to determine the effect of the scapular strengthening exercise using elastic band on balance and quality of life in the old people.

Balance ability is closely related to muscle strength (Granacher et al., 2013), the muscles around the scapula are related to lateral core muscle (Hazar Kanik et al., 2017), and stability of trunk muscle affects shoulder muscle activity (Biscarini et al., 2019). In addition, the position and shape of the scapula is an important factor affecting the trunk (Biscarini et al., 2019). In the old people, curvature of the spine occurs mainly due to weakening of the muscles around the scapula, which increases postural sway and increases the risk of falls (Sinaki et al., 2005). Markovic et al. (2015) found that feedback-based balance and core resistance training is effective for muscle function and balance in the old people. They reported that the sway distance (mediolateral) reduction through increasing trunk muscle strength eventually improved the balance ability. As a result of this study, path velocity, path length, and path area of the static balance significantly decreased after intervention when the eyes were opened and closed. It is thought that the resistance given to the muscles around the scapula through the band affected the improvement of the trunk and the overall strength of the body, thereby improving the static balance ability.

Dynamic balance is the ability to maintain postural control while a person's center of mass moves out of the support surface (Freund et al., 2019). With age, flexibility and range of joint motion decrease, resulting in poor dynamic balance of the old people (Kim et al., 2018). Lee et al. (2015) reported that the old people had a decreased balance using Y-balance compared to middle-aged women. This can be attributed to the various factors affecting balance, i.e., range of motion, muscle strength, posture, deformation, function, and psychological states (Menz et al., 2005; Spink et al., 2011). Bouillon et al. (2011) reported that the PM performed better than the anteromedial when measuring balance using star excursion balance test in the young adult and the old people. Gribble et al. (2012) and Hoch et al. (2016) reported that patients with chronic ankle instability received the highest score in the PM direction among the three directions of ANT, PM, and PL when applying the Y-balance. In this study, we found that the ANT and PM significantly increased in the experimental group. In particular, the ANT of the experimental group showed the highest value after intervention, which is a result of creating more knee flexion to maintain balance (Lee et al., 2015). In the control group, ANT, $\mathrm{PM}$, and PL were all increased. It is thought that the intervention applied to the control group increased the flexibility of the ankle.

Exercise is essential for active healthy aging without functional impairment (Van Roie et al., 2010) and contributes to improving quality of life (Acree et al., 2006; Atlantis et al., 2004; Daskapan et al., 2005). Fraga et al. (2011) reported that the walking program for old women over the age of 60 is effective in improving the 
quality of life. Liu and So (2008) reported that when 12 weeks of Tai Chi exercise was applied to the old people, $\mathrm{PH}$ and $\mathrm{GH}$ were improved. In this study, the $\mathrm{PH}, \mathrm{GH}$, and $\mathrm{MH}$ were improved after applying the scapular strengthening exercise program using an elastic band. These results are consistent with the results of previous studies, and it is thought that the improvement of $\mathrm{PH}$ through exercise had a positive effect on health perception and thus the quality of life. This study is thought to have helped to improve the physical and $\mathrm{MH}$ areas of the quality of life through regular exercise and active communication of participants through group exercise.

In summary, the scapular strengthening exercise program using the elastic band improved the balance and quality of life of the old people. This is thought to be the result of the improvement of kyphotic posture through scapular strengthening exercise. Therefore, it could be suggested as an intervention program for improving the balance ability of the old people. As a limitation of this study, it is difficult to generalize the contents because the number of subjects is small, and the intervention period is short. In addition, there was a limitation in applying the same strength by applying the elasticity of the elastic band according to the physical condition of the old people. Therefore, in future studies, studies in which these limitations are supplemented should be conducted.

\section{CONFLICT OF INTEREST}

No potential conflict of interest relevant to this article was reported.

\section{ACKNOWLEDGMENTS}

This work was supported by Kyungnam University Foundation Grant, 2019.

\section{REFERENCES}

Acree LS, Longfors J, Fjeldstad AS, Fjeldstad C, Schank B, Nickel KJ, Montgomery PS, Gardner AW. Physical activity is related to quality of life in older adults. Health Qual Life Outcomes 2006;4:37.

Atlantis E, Chow CM, Kirby A, Singh MF. An effective exercise-based intervention for improving mental health and quality of life measures: a randomized controlled trial. Prev Med 2004;39:424-434.

Bechshøft RL, Reitelseder S, Højfeldt G, Castro-Mejía JL, Khakimov B, Ahmad HF, Kjær M, Engelsen SB, Johansen SM, Rasmussen MA, Lassen AJ, Jensen T, Beyer N, Serena A, Perez-Cueto FJ, Nielsen DS, Jes- persen AP, Holm L. Counteracting age-related loss of skeletal muscle mass: a clinical and ethnological trial on the role of protein supplementation and training load (CALM Intervention Study): study protocol for a randomized controlled trial. Trials 2016;17:397.

Biscarini A, Contemori S, Grolla G. Activation of scapular and lumbopelvic muscles during core exercises executed on a whole-body wobble board. J Sport Rehabil 2019;28:623-634.

Bouillon LE, Baker JL. Dynamic balance differences as measured by the star excursion balance test between adult-aged and middle-aged women. Sports Health 2011;3:466-469.

Brown M, Sinacore DR, Binder EF, Kohrt WM. Physical and performance measures for the identification of mild to moderate frailty. J Gerontol A Biol Sci Med Sci 2000;55:350-355.

Cheng PT, Wu SH, Liaw MY, Wong AM, Tang FT. Symmetrical bodyweight distribution training in stroke patients and its effect on fall prevention. Arch Phys Med Rehabil 2001;82:1650-1654.

Choi CJ, Lim HW, Park MK, Cho JG, Im GJ, Chae SW. Does the kyphotic change decrease the risk of fall? Clin Exp Otorhinolaryngol 2011;4:118121.

Daskapan A, Tuzun EH, Eker L. Relationship between physical activity level and health related quality of life among university students. Saudi Med J 2005;26:1026-1028.

Fraga MJ, Cader SA, Ferreira MA, Giani TS, Dantas EH. Aerobic resistance, functional autonomy and quality of life (QoL) of elderly women impacted by a recreation and walking program. Arch Gerontol Geriatr 2011;52:40-43.

Freund JE, Stetts DM, Oostindie A, Shepherd J, Vallabhajosula S. Lower Quarter Y-Balance Test in healthy women 50-79 years old. J Women Aging 2019;31:475-491.

Geirsdottir OG, Arnarson A, Briem K, Ramel A, Tomasson K, Jonsson PV, Thorsdottir I. Physical function predicts improvement in quality of life in elderly Icelanders after 12 weeks of resistance exercise. J Nutr Health Aging 2012;16:62-66.

Granacher U, Lacroix A, Muehlbauer T, Roettger K, Gollhofer A. Effects of core instability strength training on trunk muscle strength, spinal mobility, dynamic balance and functional mobility in older adults. Gerontology 2013;59:105-113.

Gribble PA, Hertel J, Plisky P. Using the Star Excursion Balance Test to assess dynamic postural-control deficits and outcomes in lower extremity injury: a literature and systematic review. J Athl Train 2012;47:339357.

Han CW, Lee EJ, Iwaya T, Kataoka H, Kohzuki M. Development of the Korean version of Short-Form 36-Item Health Survey: health related QOL of healthy elderly people and elderly patients in Korea. Tohoku J Exp Med 2004;203:189-194. 
Hazar Kanik Z, Pala OO, Gunaydin G, Sozlu U, Alkan ZB, Basar S, Citaker $S$. Relationship between scapular muscle and core endurance in healthy subjects. J Back Musculoskelet Rehabil 2017;30:811-817.

Hoch MC, Gaven SL, Weinhandl JT. Kinematic predictors of star excursion balance test performance in individuals with chronic ankle instability. Clin Biomech (Bristol, Avon) 2016;35:37-41.

Huang SW, Ku JW, Lin LF, Liao CD, Chou LC, Liou TH. Body composition influenced by progressive elastic band resistance exercise of sarcopenic obesity elderly women: a pilot randomized controlled trial. Eur J Phys Rehabil Med 2017;53:556-563.

Hyndman D, Ashburn A, Yardley L, Stack E. Interference between balance, gait and cognitive task performance among people with stroke living in the community. Disabil Rehabil 2006;28:849-856.

Kado DM, Huang MH, Karlamangla AS, Barrett-Connor E, Greendale GA. Hyperkyphotic posture predicts mortality in older community-dwelling men and women: a prospective study. J Am Geriatr Soc 2004;52:1662-1667.

Kaufman KR, Hughes C, Morrey BF, Morrey M, An KN. Gait characteristics of patients with knee osteoarthritis. J Biomech 2001;34:907-915.

Kim D, Park G, Kuo LT, Park W. The effects of pain on quadriceps strength, joint proprioception and dynamic balance among women aged 65 to 75 years with knee osteoarthritis. BMC Geriatr 2018;18:245.

Lee DK, Kang MH, Lee TS, Oh JS. Relationships among the Y balance test, Berg Balance Scale, and lower limb strength in middle-aged and older females. Braz J Phys Ther 2015;19:227-234.

Liao CD, Tsauo JY, Huang SW, Ku JW, Hsiao DJ, Liou TH. Effects of elastic band exercise on lean mass and physical capacity in older women with sarcopenic obesity: a randomized controlled trial. Sci Rep 2018; 8:2317.

Liberman K, Forti LN, Beyer I, Bautmans I. The effects of exercise on muscle strength, body composition, physical functioning and the inflammatory profile of older adults: a systematic review. Curr Opin Clin Nutr Metab Care 2017;20:30-53.

Liu M, So H. Effects of Tai Chi exercise program on physical fitness, fall related perception and health status in institutionalized elders. Taehan Kanho Hakhoe Chi 2008;38:620-628.

Magarey ME, Jones MA. Dynamic evaluation and early management of altered motor control around the shoulder complex. Man Ther 2003; 8:195-206

Markovic G, Sarabon N, Greblo Z, Krizanic V. Effects of feedback-based balance and core resistance training vs. pilates training on balance and muscle function in older women: a randomized-controlled trial. Arch Gerontol Geriatr 2015;61:117-123.

Menz HB, Morris ME, Lord SR. Foot and ankle characteristics associated with impaired balance and functional ability in older people. J Gerontol A Biol Sci Med Sci 2005;60:1546-1552.

Moezy A, Sepehrifar S, Solaymani Dodaran M. The effects of scapular stabilization based exercise therapy on pain, posture, flexibility and shoulder mobility in patients with shoulder impingement syndrome: a controlled randomized clinical trial. Med J Islam Repub Iran 2014; 28:87.

Plisky PJ, Gorman PP, Butler RJ, Kiesel KB, Underwood FB, Elkins B. The reliability of an instrumented device for measuring components of the star excursion balance test. N Am J Sports Phys Ther 2009;4:92-99.

Prasertsakul T, Kaimuk P, Chinjenpradit W, Limroongreungrat W, Charoensuk $W$. The effect of virtual reality-based balance training on motor learning and postural control in healthy adults: a randomized preliminary study. Biomed Eng Online 2018;17:124.

Regterschot GR, Folkersma M, Zhang W, Baldus H, Stevens M, Zijlstra W. Sensitivity of sensor-based sit-to-stand peak power to the effects of training leg strength, leg power and balance in older adults. Gait Posture 2014;39:303-307.

Rogers ME, Rogers NL, Takeshima N, Islam MM. Methods to assess and improve the physical parameters associated with fall risk in older adults. Prev Med 2003;36:255-264.

Shiravi S, Letafatkar A, Bertozzi L, Pillastrini P, Khaleghi Tazji M. Efficacy of abdominal control feedback and scapula stabilization exercises in participants with forward head, round shoulder postures and neck movement impairment. Sports Health 2019;11:272-279.

Sinaki M, Brey RH, Hughes CA, Larson DR, Kaufman KR. Balance disorder and increased risk of falls in osteoporosis and kyphosis: significance of kyphotic posture and muscle strength. Osteoporos Int 2005; 16:1004-1010.

Spink MJ, Fotoohabadi MR, Wee E, Hill KD, Lord SR, Menz HB. Foot and ankle strength, range of motion, posture, and deformity are associated with balance and functional ability in older adults. Arch Phys Med Rehabil 2011;92:68-75.

Van Roie E, Delecluse C, Opdenacker J, De Bock K, Kennis E, Boen F. Effectiveness of a lifestyle physical activity versus a structured exercise intervention in older adults. J Aging Phys Act 2010;18:335-352. 